\title{
Legal regulation of tourism activities in rural areas
}

\author{
Ludmila Spektor ${ }^{1, *}$ and Eduard Genzuk ${ }^{1}$ \\ ${ }^{1}$ Institute of Service and Entrepreneurship (branch) of DSTU in Shakhty, 110 Shevchenko str., \\ Shakhty, Rostov region, 346500, Russia
}

\begin{abstract}
Rural territories may benefit from the entrepreneurial dynamics created by small tourism businesses, especially if associated to lifestyle motivations of respective entrepreneurs. Despite distrust amongst some researchers regarding small tourism businesses' contribution to rural economies, their potential role for enhancing rural development, should not be neglected.Rural tourism has grown in many rural regions worldwide and today it is a stable driver of rural social and economic development. In this paper we argue that rural tourism growth should follow a divergent path from sea tourism development, because failing to do so would likely push rural tourism toward mass tourism, resulting in a harmful twofold effect: given that mass tourism requires built-up expansion to accommodate larger number of tourists, in rural areas this will certainly compromise the beauty of the landscape which is a fundamental local resource for rural tourism; built-up growth required to satisfy seaside mass tourism expectations is often characterized as holiday resorts, artificial villages, and residential high-density condos, with a consequent loss of cultural-traditional identity, which is also a key element for rural landscapes' attractiveness.
\end{abstract}

\section{Introduction}

Modern tourism is a combination of various types of activities aimed at creating goods and providing services to travelers in order to generate income due to the use of various objects of a natural, historical, cultural and other nature as unique places of display and recreation that differ in the natural and cultural characteristics of a country or region. In the scientific discourse, tourism attracts the attention of many researchers: sociologists, economists, marketers, lawyers, and so on, who consider its individual components. At the same time, tourism as a whole is not sufficiently studied as an object of state-legal influence and a subject of legal regulation, which has its own unique specifics. In the latter capacity, tourism is "politically significant government decisions" that actualizes the study of the phenomenon of tourism from the perspective of legal-political science and application of its generalizations in the further development of scientific knowledge in the tourism and travel industry practice.

\footnotetext{
*Corresponding author: shpigunova96@mail.ru
} 


\section{Methodology}

When writing an educational and research work the method of analysis and synthesis is used: First, we analyze disparate legal and literary sources, information from which is synthesized to draw conclusions and form hypotheses.

\section{Results of the research}

Traditionally the subject of legal regulation is understood as a qualitatively homogeneous type of public relations which is affected by the norms of a particular branch of law. The subject of legal regulation along with the method of regulation, acts as a criterion for the division of legal norms by industry due to its objective nature, which follows from the very existence of specific relations between people in society about something. By regulating certain social relations the law fixes the established social practice, acts as a "powerful organizing factor, brings special certainty and stability to the relevant sphere of public and state life", thanks to which public relations acquire a legal form becoming legal relations [1].

For example, the legal regulation of relations in the field of tourism forms tourism legislation, while it is premature to talk about tourism law as a branch of law. The legal regulation of tourism is carried out both by national law and by international legal acts. The norms of international law governing relations in the field of tourism are not codified and are often contained in various documents [2]. A number of international acts form the basis of international legal regulation of relations related to tourism and travel. Article 24 of the Universal Declaration of Human Rights of 1948 It establishes that " everyone has the right to rest in their free time, including a reasonable limitation of working hours and periodic paid leave." Article 7 of the International Covenant on Economic, Social and Cultural Rights of 1966 reflects the obligation of States to ensure the right to "rest, reasonable restriction of working hours and periodic paid leave, as well as payment for public holidays" [3]. The principles set out in subsequent international documents of a recommendatory nature - the Manila Declaration on World Tourism, the Charter of Tourism, the Tourist Code and othersemphasize the humane nature of tourism and its importance as a means of improving the quality of life of peoples, an essential factor in strengthening peace and international cooperation [4].

Currently, tourism is interconnected with many state, public and private interests and has a significant impact on society (economic sphere, leisure, consumer culture, axiological guidelines, social ties and communications, lifestyle, etc.) [5]. Tourism policy is one of the types of macroeconomic policy of the state, and its impact on tourism is carried out through state regulation of tourist activities." At the same time it should be taken into account that "for many years, extensive factors of economic growth prevailed in Russian tourism implying "the involvement in tourist production of additional factors (labor, capital, land) that function at the same quality level."

Table 1. Chart. Structure of tourism management in Russia.

\begin{tabular}{|l|l|}
\hline 1. & Ministry of Sports, Tourism and Youth Policy \\
\hline 2. & Federal Agency for Tourism \\
\hline 3. & Regional ministries and departments \\
\hline
\end{tabular}

The tourism sector is organically interwoven into the structure of the emerging civil society as a society based on private property, interests, needs and social communication. Civil society institutions are ideally designed to serve the implementation of private initiatives of citizens, the disclosure of their potential as creative individuals which is also characteristic of tourism as a form of recreation and active pastime. The transformation of social interests leads to a greater differentiation of consumption needs, which also affects the 
tourist preferences of citizens. Such forms of tourism as extreme, business, event, urban, rural tourism are developing, and sports types of tourism, which include not only visiting sports events, but also direct participation in them, are also very popular. So it is possible to highlight the most growing and gaining popularity among the tourists of the sector of rural tourism in Russia [6].

Tourism and Rural Development is the theme of World Tourism Day 2020, as stated in the Message of the UNWTO Secretary-General. We are talking about the development of various types of tourism in rural areas, including the development of rural tourism itself. This direction is promising, the development of rural tourism is mentioned in a number of normative documents of the World Tourism Organization, as well as strategic documents of different states. The organization of tourism in rural areas depends on a number of factors:

1. The social factor. It includes the personnel potential of the territory, which has information about the presence or absence of professionals in the field of tourism, about the experience and level of education, about the possibility of training and retraining. The social factor also includes the opinion and initiative of citizens in the development of tourism in this territory [7].

2. The economic factor. This is the presence of organizations that are ready to carry out activities in the field of tourism in rural areas. These are also existing and potentially necessary infrastructure resources: roads, overnight accommodation, garbage containers, toilets, etc. These facilities are often not available in rural areas, which creates situations for the development of tourism on motorhomes and campers, with full or partial equipment necessary for long-term movement and living in it [8].

3. Natural-historical factor. This is the presence of attractive attractive places available for tourists to visit. In rural tourism, this is mainly the natural potential of the territory: forest, river, lake, sea, mountains and hills, etc. Attractions can also be preserved buildings and structures, places with a rich history. There are other factors that influence the formation of tourist activity in rural areas but the ones presented above are of the greatest importance [14].

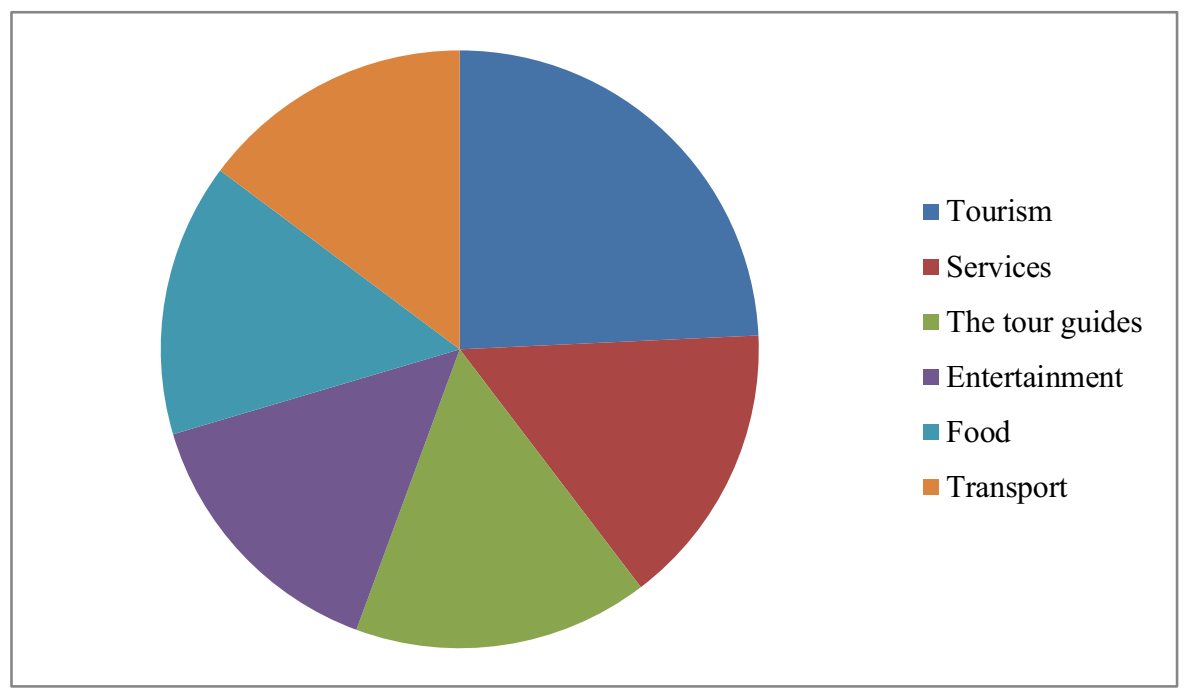

Fig. 1. Structure of tourism.

\section{Discussion of results}

On the example of one of the villages of the Republic of Karelia we will clearly reveal the manifestation of these factors. Village Karseva located in Pudozhsky district in the South- 
East of Republic of Karelia. It is part of the Krasnoborsky rural settlement and is geographically located near two specially protected natural areas of regional significance (SPNA) - Vodlozersky National Park and reserve "Muromsky". The reserve "Muromsky" is located $17 \mathrm{~km}$ from the village, you can only get to it by water or by bypassing the village through other localities. Since the 1990s, the Nature Reserve has become a point of attraction for scientists and tourists, and in recent years for bloggers and off - road enthusiasts. The fact is that on the territory of the Reserve there are two major objects-the Onega petroglyphs and the Murom Spaso-Preobrazhensky Monastery. More popular are petroglyphs-rock carvings created more than 6000 years ago. They are found on a group of islands and headlands of the lake, the largest areas of petroglyph deposition are near the abandoned lighthouse at Cape Besov Nos and Cape Peri Nos. The social factor of the organization and development of tourism in this territory is represented by local residents who actively participate in communication with visitors. The psychology of local residents was formed in such a way that due to the lack of work and the closure of the only major organization in the 1990s-the state farm "Onezhsky", tourism became a new vector of development of this territory [9].

Local residents are willing to help visitors and offer their services: delivery by motor boat to the petroglyphs, sale of local products (berries/mushrooms/fish/egg/milk), conduct excursions and offer overnight accommodation. Experience in tourism for several decades exists, it is difficult to judge the quality, but the reviews on social networks are quite positive. $1 \%$ of the approximately two hundred residents have a tourist education. In Karelia the opportunity to learn and undergo training in the tourism sector in Petrozavodsk, the capital of Karelia, Petrozavodsk state is the University that implements the areas of training Tourism and Hospitality in higher education programs of undergraduate and graduate programs, intramural and extramural [12]. Petr also implements a distance learning format for additional professional education programs. The College of Technology and Entrepreneurship implements secondary vocational education programs in Hotel Business and Hotel Service. Since the main attraction of this territory is a specially protected natural area, the requirements for service personnel in this territory are higher. Knowledge and skills in the field of ecology, nature management and ecotourism are welcome [10].

Any mobile homes were considered both with a built-in living space in the vehicle, and trailers equipped for living". This type of transport frees users from booking hotels but increases the demand for equipped parking lots. Well, and the last, natural-historical factor. Here it is represented by the above-mentioned proximity to protected areas, as well as forest, small lakes and the Chernaya River[13]. The attractors for a long time was the poor condition of roads on the way Karcheva - Cape Besov [15]. Tourists came here in search of extreme driving off-road and checking the reliability of their car. There are a lot of such videos in the public domain. However, this caused huge damage to the territory of the Reserve. Bonfires were built on the rocks with petroglyphs, after the rest there was garbage, etc. This problem was partially solved by the Directorate of Specially Protected Natural Territories of the Republic of Karelia with the appointment of inspectors for the protection of the territory. Partly because of the destruction of the bridge over the river, on the way to the petroglyphs [11].

\section{Conclusions}

Tourism being an area regulated by civil, administrative, international, transport and other law is currently not fully explored in order to become an independent scientific direction. I. F. Ignatieva writes: "Apparently, the science of tourism is going through a period of its formation, it is still too early to talk about a holistic science of tourism, but the movement in this direction can be traced; this is manifested, for example, in the fact that there are concepts that propose to separate the science of tourism into a separate field, but usually we are talking 
about reducing this science to a single economy." In this regard, it is possible to identify a number of features that can contribute to the formation of this field of knowledge and a more complete understanding of tourism as a subject of legal regulation: the heterogeneity of tourism as a sphere of public relations, social and cultural phenomenon; a relatively short history of the formation and development of the tourism industry; insufficient attention to the non-economic components of tourism, etc. However, for all their diversity and ambiguity, these difficulties are reduced to two main factors:

- the complexity of the subject matter, since it is multifaceted and, therefore, contains a number of inaccurate formulations, due to the fact that there is still no consensus on the definition of tourism, which is complicated by the conditions of cross-regulation by many branches of law;

- the fact that tourism, being part of the research of various scientific disciplines, has not yet been subjected to a comprehensive systematic analysis in the context of legal theory, which may be problematic for law enforcement practice, so it is necessary to establish boundaries within which it will be possible to form approaches to the study of it as an object of legal influence

Thus, the territories located near protected areas, having the above factors, have opportunities for tourism development. On the example of one locality, an example of the historical development of the territory since the 1990s, since the complete closure of the cityforming enterprise was presented. Tourism has become a new vector of development of the territory due to the specially protected natural area located near.

\section{References}

1. T. Mihalic, J. Clean. Prod. 111, 461-470 (2016)

2. E. Agyeiwaah, B. McKercher, W. Suntikul, Tourism Manage. Perspect. 24, 26-33 (2017)

3. M. Trinitat Rovira Soto, S. Anton Clavé, Land Use Policy 68, 117-132 (2017)

4. A. De Montis, A. Ledda, V. Serra et al., Land Use Policy 62, 113-131 (2017)

5. P.T. Roundy, M. Bradshaw, B.K. Brockman, Journal of Business Research 86, 1-10 (2018)

6. F. Randelli, F. Martellozzo, Land Use Policy 86, 387-398 (2019)

7. Z. Mottiar, K. Boluk, C. King, Annals of Tourism Research 68, 77-88 (2018)

8. E. Kastenholz, Sage Handbook of tourism management 72, 493-515 (2018)

9. A. Kallmuenzer, W. Nikolakis, M. Peters, J. Zanon, Journal of Sustainable Tourism 26(7), 1204-1221 (2018)

10. Y. Liu, Y. Li, Revitalize the world's countryside Nature 548, 275-277 (2017)

11. D. Dryglas, M. Salamaga, Journal of Destination Marketing \& Management 9, 234-246 (2018)

12. E. Sthapit, Scandinavian Journal of Hospitality and Tourism 19(2), 115-139 (2019)

13. D. Soares da Silva, E. Figueiredo, C. Eusébio, M.J. Carneiro, Journal of Rural Studies 44 (2016), pp. 77-88

14. M. Qiu, J. Zhang, H. Zhang, C. Zheng, Journal of Travel \& Tourism Marketing 35(7), 869-881 (2018)

15. V. Patwardhan, M.A. Ribeiro, V. Payini et al., Journal of Travel Research 59(1), 3-21 (2020)

16. Protection of coastal areas in Italy: Where do national landscape and urban planning legislation fail? Land Use Policy 66, 80-89 (2017) 